\section{Pseudoautosomale Region}

\section{J. Arnemann}

Abteilung Molekulargenetik, Labor Dr. Wisplinghoff, Köln, Deutschland

\section{Synonym(e) PAR}

Englischer Begriff pseudoautosomal region

Definition Die pseudoautosomalen Regionen (PAR) umfassen die distalen, homologen Bereiche der beiden ungleichen Geschlechtschromosomen X und Y.

Beschreibung Die beiden Geschlechtschromosomen haben sich während der Genomevolution divergent entwickelt und zeigen über weite Strecken keine ausgeprägte Homologie zueinander. Nur in den distalen Abschnitten des kurzen und des langen Chromosomenarms von $\mathrm{X}$ und $\mathrm{Y}$ findet sich jeweils eine Region mit funktionell gleichen Genen, die auf Sequenzebene homolog zueinander ist. Diese Regionen paaren während der Meiose miteinander, und es kommt zu einem obligaten Crossing over und damit zur Rekombination, während die übrigen Abschnitte aufgrund der fehlenden Homologie nicht miteinander paaren. Das obligate Crossing over während der Meiose entspricht dem Meioseverhalten von autosomalen Chromosomen, weshalb diese Regionen auch als pseudoautosomale Regionen (PAR), namentlich PAR1 (kurzer Arm) und PAR2 (langer Arm), bezeichnet werden. Die pseudoautosomalen Regionen des X-Chromosoms entgehen der X-Inaktivierung.

\section{Literatur}

Alberts et al (2002) Molecular biology of the cell, 4. Aufl. Garland Science, New York 